\title{
COMUNICACIÓN, ESTRATEGIA POLÍTICA Y PARTICIPACIÓN
}

\author{
José Javier Rueda \\ Periodista, \\ Heraldo de Aragón
}

Cómo citar este artículo / Citation: Rueda, J. J. (2021).

Comunicación, estrategia política y participación.

Palacios Romeo, F. y Cebrián Zazurca, E. (coords.)

Elección y representación: una conjunción compleja. Perspectivas y problemas de los regímenes electorales en España, Colección Obras colectivas, Fundación Manuel Giménez Abad, Zaragoza.

DOI: https://doi.org/10.47919/FMGA.OC21.0304

SUMARIO: I. INTRODUCCIÓN - II. LA CIVILIZACIÓN DEL ESPECTÁCULO FRIVOLIZA LA POLÍTICA, LA COMUNICACIÓN POLÍTICA Y EL PERIODISMO - III. AUGE DEL RELATO Y DE LAS EMOCIONES FRENTE A LA RAZÓN - IV. INTERNET GENERA UNA REVISIÓN GLOBAL DE LA COMUNICACIÓN POLÍTICA - V. GANA PROTAGONISMO EL ACTIVISMO CIUDADANO - VI. INTERNET HA CAMBIADO TAMBIÉN EL NEGOCIO DE LA INFORMACIÓN - VII. MULTIPLICACIÓN DE BULOS Y NOTICIAS FALSAS VIII. LA COMUNICACIÓN BIDIRECCIONAL INCREMENTA LA VOLATILIDAD - IX. LA GRAN MANIPULACIÓN COMUNICATIVA: DEL CONFLICTO SOCIAL AL IDENTITARIO - X. PROFESIONALIZACIÓN DE LA ASESORÍA Y LA COMUNICACIÓN POLÍTICAS EN TORNO A LOS HIPERLIDERAZGOS - XI. UNA COMUNICACIÓN POLÍTICA VOLCADA EN EL MANEJO DE DATOS XII. BIBLIOGRAFÍA 


\section{INTRODUCCIÓN}

Walter Lippmann, el célebre periodista estadounidense, relata en su obra Public Opinion una anécdota de lo ocurrido en una lejana isla al inicio de la Primera Guerra Mundial:

En 1914, un grupo de ciudadanos ingleses, franceses y alemanes residía en una isla situada en medio del océano. No era posible comunicarse con ellos mediante cablegramas y el barco de vapor del servicio de correos británico solo arribaba una vez cada 60 días. Ya era septiembre, pero aún no había venido y los isleños continuaban comentando las noticias leídas en el último periódico, que hablaba del juicio de Madame Caillaux, cada vez más próximo, por el asesinato de Gaston Calmette. Por tanto, el entusiasmo era mayor de lo habitual aquel día de mediados de septiembre, cuando toda la colonia se reunió en el muelle para escuchar de boca del capitán cual había sido el veredicto. Así supieron que los ingleses y franceses que había entre ellos llevaban más de seis semanas luchando contra sus vecinos alemanes en nombre de la inviolabilidad de los tratados. Durante seis extrañas semanas habían actuado como si fueran amigos, cuando en realidad eran enemigos. (Lippmann, 2003, p. 25).

Lippmann ilustraba con ese episodio un principio esencial de la vida moderna: sabemos del mundo que nos rodea de forma indirecta, a través de las noticias que nos llegan y que tendemos a considerar fiel reflejo de la realidad. Por eso, el analista americano asimilaba el ciudadano moderno al cautivo encadenado en la alegoría de la caverna de La República de Platón, que solo podía ver las sombras del exterior que proyectaba un fuego, pero no la realidad misma. En la actualidad, los medios de comunicación de masas y las redes sociales transmiten directamente al ciudadano, de forma casi instantánea, imágenes y testimonios directos de acontecimientos próximos y también muy distantes. Pero es una ilusión pensar que tales avances nos han sacado de la caverna de Platón: la mayor parte de los asuntos que nos afectan son complejos, en el mundo ocurren muchos hechos distintos y la capacidad del ser humano de comprender y asimilar es limitada. Por eso el ciudadano sigue dependiendo de las fuentes de información y opinión de las que se nutre y que pueden estar más o menos manipuladas. Por ello, en el ámbito de la comunicación social conviven, junto con algunos medios de calidad y rigurosa vocación informativa, 
un abigarrado microcosmos de periódicos, canales de televisión, medios digitales, comunicadores e incluso simples ciudadanos que, ya sea por razones políticas o por motivos económicos, libran una batalla sin cuartel por captar la atención del ciudadano y transmitirle una particular visión de la realidad tan fiel o tan tergiversada y sectaria como sea preciso para alcanzar sus fines. Para Lippmann, que los ciudadanos y la opinión pública tuvieran información exacta e imparcial constituía el "problema básico de la democracia". Casi un siglo después, lo sigue siendo. Por eso mismo, los dirigentes, los que aspiran a gobernar y, en general, las élites del poder siempre han mostrado gran interés por controlar lo que se dice, cómo se dice y cuándo se dice en los medios de comunicación.

La Historia demuestra que el poder siempre ha comunicado, sea a través de una danza, una pirámide, un arco de triunfo o, en los dos últimos siglos, a través de una rueda de prensa o una filtración periodística. El objetivo fue y es influir. Ahora bien, la comunicación política en un sentido moderno surge con el liberalismo. Desde el siglo XVIII, el parlamentarismo facilita la entrada en los órganos de deliberación de un actor político fundamental: la prensa. Con la libertad de prensa, aunque tenga muchas limitaciones, el poder se ve obligado a asumir que hay más actores que participan en el desarrollo de los acontecimientos. A partir de ese momento, los medios de comunicación juegan en cuanto a su capacidad de construcción de la realidad, incluida la realidad política que es percibida por los ciudadanos a través de la información que vierten.

Los gobernantes y los aspirantes a serlo van entendiendo que los medios de comunicación no ofrecen tanto información como persuasión por mucho desvelo que se tenga en ser fieles a la realidad. La objetividad periodística es un mito. Como Bernal y Chillón señalan, "ningún mensaje informativo puede ser objetivo, apolítico, imparcial, neutral e independiente porque su emisor, en el acto de selección de los datos informativos, del registro, elaboración y transmisión, discrimina, ordena, manipula e incluso interpreta la realidad que pretende comunicar a su auditorio" (citado en Yanes, 2009, p. 46). Es inevitable "manipular" la información para hacerla llegar al público: hay que decidir qué información se busca y qué canales de recepción de información "bruta" se utilizan, hay que seleccionarla, dedicarle mayor o menor espacio, titularla, acompañarla o no con imágenes e interpretarla con piezas de análisis. Los 
medios de comunicación dicen y callan, ofrecen una selección de noticias y datos que guía a la ciudadanía para opinar esto o aquello, incluso para opinar de esto y aquello, también ignoran u ocultan otros datos y noticias. Solo la pluralidad ideológica de los medios palía parcialmente esta limitación.

La noticia que se consume a diario como un objeto cultural no es un simple reflejo neutral de hechos que acontecen, sino un discurso que representa y construye la realidad social de manera simultánea. La noticia, como construcción de lo que sucedió, implica la selección de ciertos elementos del "mundo por significar", que solo al ser descritos, relatados, y explicados, adquieren sentido y se transforman en un "mundo significado" (Charaudeau, 2003, p. 50). Para realizar esta construcción discursiva, los medios seleccionan, transforman y narran los acontecimientos del mundo real siempre bajo una determinada perspectiva, que se deriva, en parte, de los criterios de noticiabilidad y de otras convenciones del género periodístico, pero también, de sus posturas ideológicas como instituciones con un anclaje social, económico y político. Además, el trascurrir de la noticia desde que se produce hasta que se manufactura en la redacción de un medio de comunicación es un proceso cada vez más sometido al control de intermediarios por las dificultades de acceso directo a los hechos o a las fuentes, y por las operaciones de manipulación de unos y otros. Noam Chomsky proponía en los años ochenta cinco mecanismos de selección de noticias, cinco "filtros": la concentración de la propiedad, la publicidad, la dependencia informativa, las contramedidas y el anticomunismo (Chomsky y Herman, 1990, p. 22). De hecho, como hemos dicho, el control de los medios de comunicación, más o menos evidente, es considerado por todos los regímenes como una necesidad fundamental: en las democracias, porque se basan en la opinión pública; en las dictaduras, porque se fundamentan en su manipulación. Manuel Castells es taxativo a ese respecto: "La forma esencial de poder está en la capacidad para modelar la mente. [...]. Si la batalla primordial para la definición de las normas de la sociedad y la aplicación de dichas normas a la vida diaria gira en torno al modelado de la mente, la comunicación es fundamental en esta lucha, ya que es mediante la comunicación como la mente humana interactúa con su entorno social y natural" (Castells, 2009, p. 24).

Mención aparte merece el fenómeno de la propaganda, tan antiguo como la propia humanidad, aunque fue en el siglo $X X$ cuando se aplicó de una forma 
sistemática y organizada aprovechando la irrupción de los grandes medios de comunicación de masas (prensa escrita, radio, cine, televisión y el primer internet) y por la necesidad que tuvieron los regímenes democráticos de lograr un consenso social que respaldase sus acciones. La guerra hispano-cubana de 1898 fue el precedente de una tendencia política que se ha hecho habitual en el siglo XX y el XXI: el intento de manipular a la opinión pública a través de los medios de comunicación para convencerla de la necesidad de una determinada decisión. Los gobernantes de los regímenes democráticos se siguen sirviendo de la "estrategia del miedo", de la "razón de Estado", de los principios de "seguridad nacional" y de otras viejas palancas de control, como las presiones administrativas o las amenazas de recorte de publicidad, para intentar manipular a los medios de comunicación (Pizarroso, 2005).

Varios especialistas han interpretado el papel de los medios como agentes activos e independientes, el "perro guardián" del interés público frente al gobierno (Graber, 1997). Otros autores ven a los medios solo como un componente más de la compleja estructura del poder político. La prensa sería así un instrumento que tiende a apoyar las posiciones de las élites, sin ofrecer disensión a las decisiones gubernamentales (Hallin, 2009). El modelo de propaganda o de fabricación del consenso definido por Herman y Chomsky en su libro apuntará en esta dirección al igual que los trabajos de David Miller (Miller, 2004). La mayoría de los investigadores, no obstante, adopta una postura intermedia, según la cual los medios de calidad no son ni enemigos abiertos ni agentes de la propaganda de los gobiernos. La relación entre los gobernantes y los medios de comunicación es calificada de "simbiótica", donde ambos cooperan y se apoyan entre sí, logrando beneficios mutuos (Orren 1986; O’Heffernan, 1991). También existe la teoría de que los medios de comunicación tienen un comportamiento sistémico (Luhmann, 2005) con unas determinadas rutinas y condicionamientos (tecnológicos, presupuestarios, etc.) que pueden provocar una cobertura sesgada en algunos casos (Rueda, 2015).

Dentro de estas coordenadas generales, la comunicación política, que como toda comunicación es un procedimiento dinámico, presenta en la actualidad nuevas tendencias vinculadas en buena parte a la americanización de las campañas, influida por la entrada de la televisión, y a las transformaciones que están generando el creciente protagonismo de internet y las redes sociales. 
Apuntamos aquí algunas de forma somera y sustentadas esencialmente en el quehacer periodístico en la redacción de un diario:

1. La civilización del espectáculo frivoliza la política, la comunicación política y el periodismo.

2. Auge del relato y de las emociones frente a la razón.

3. Internet genera una revisión global de la comunicación política.

4. Gana protagonismo el activismo ciudadano.

5. Internet ha cambiado también el negocio de la información.

6. Multiplicación de bulos y noticias falsas.

7. La comunicación bidireccional incrementa la volatilidad.

8. La gran manipulación comunicativa: del conflicto social al identitario.

9. Profesionalización de la asesoría y la comunicación políticas en torno a los hiperliderazgos.

10. Una comunicación política volcada en el manejo de datos.

\section{LA CIVILIZACIÓN DEL ESPECTÁCULO FRIVOLIZA LA POLÍTICA, LA COMUNICACIÓN POLÍTICA Y EL PERIODISMO}

Hoy prima lo visual sobre lo textual. La ciudadanía solo conecta con lo que le entretiene. Las generaciones del mando a distancia, el de la televisión, exigen que los publicistas y los políticos capten su atención. En caso contrario, cambian de canal. Por eso, también a España ha llegado lo que los anglosajones han denominado pop politics. Se trata de responder a la necesidad de acercar la gobernanza a los ciudadanos ante el problema de la creciente desafección. Consiste en que la política se incorpora como tema y los políticos como personajes a los programas de entretenimiento televisivo buscando la máxima audiencia. Adoptan los códigos y los lenguajes propios del mundo del espectáculo, donde los personalismos son fundamentales.

La "política pop" tiene diversas manifestaciones. Ahí están, por ejemplo, la incursión de artistas más o menos conocidos (Toni Cantó), el apoyo de famosos en las campañas electorales (Julio Iglesias, Antonio Banderas) o la proyección mediática de los políticos como auténticas celebridades (SarkozyBruni). Los políticos pasan a convertirse en estrellas mediáticas que construyen 
sus liderazgos a base de relatos de su vida privada, aficiones, gustos culinarios o deportivos.

Esta tendencia ha sido muy evidente en el último ciclo electoral (2015-2019). Los mítines ya no atraen a casi nadie, ni siquiera a los militantes, y en las redacciones de los periódicos apenas se les presta atención. En realidad, la nueva era de la política española gira en torno a la televisión, para los ciudadanos de más edad, y a las redes sociales, para los jóvenes. Estamos inmersos en una cultura del entretenimiento, cuyos productos evitan a sus consumidores un esfuerzo intelectual. Varios pensadores contemporáneos han descrito este fenómeno: Adorno, Kapuściński, Saramago o Vargas Llosa. El premio Nobel hispano-peruano precisamente denunciaba en Zaragoza que la cultura del entretenimiento amenaza la supervivencia de la democracia, el choque de trenes entre la cultura audiovisual y la de las ideas (Eixarch, 2019). En esta apreciación coincide con Giovanni Sartori y su conocida teoría de que la primacía de lo visible sobre lo inteligible lleva a un ver sin entender (Sartori, 1998).

En los últimos años se alcanza el culmen de la videopolítica, según la denominación de Sartori. Se han buscado máximas audiencias televisivas en plena campaña electoral a través de la aparición de los líderes políticos en los programas de entretenimiento presentados por Pablo Motos, María Teresa Campos, Ana Rosa Quintana o Bertín Osborne. Son la plasmación de esta dinámica de personalización de la política en España, con más interés por los rostros que por las ideologías. Hay una auténtica guerra por conquistar las pantallas, no a través de los debates clásicos para contrastar ideas y proyectos, sino mediante triviales programas de entretenimiento donde se pueden colar soluciones aparentemente sencillas para problemas complejos. Este exhibicionismo les liga a la telepolítica de Silvio Berlusconi y al márquetin populista de Donald Trump o Boris Johnson.

Este fenómeno tiene, al menos, dos explicaciones no excluyentes: es la respuesta a la dimensión sensible de la democracia contemporánea y es otro caso de instrumentalización de las emociones a través de la televisión. De esta forma el candidato logra llegar a diferentes tipos de audiencia y dar a conocer aspectos mundanos de su vida que logran acercarle más y conectar mejor con el electorado. 


\section{AUGE DEL RELATO Y DE LAS EMOCIONES FRENTE A LA RAZÓN}

Una de las tendencias que se ha impuesto en la política del siglo XXI es la narración de historias como medio para hacer campaña o inculcar un sistema de valores. La gente quiere escuchar historias que le distraigan y emocionen. Por eso Barak Obama ganó de forma clara las elecciones presidenciales de 2008, supo "atrapar" a los votantes con su llamamiento a todos para mejorar el país a través del lema «Sí se puede». Un ejemplo más próximo es la reiterada utilización de la metáfora del viaje a Ítaca entres los líderes independentistas de Cataluña. Se trata de un instrumento que apela a los sentimientos para conectar con el público, así las propuestas de cada candidato o de cada partido, articuladas en programas o en discursos, constituyen relatos que interpretan la realidad social.

Los grandes relatos que jalonan la historia humana, desde Homero a Cervantes y Shakespeare, contaban mitos universales y trasmitían la sabiduría acumulada por las generaciones pasadas. La narrativa política actual recorre el camino en sentido inverso, superpone sobre la realidad unos relatos artificiales que convencen a los ciudadanos de que el voto constituye una forma de estar en el mundo. La crisis de los grandes relatos unificadores (la llustración, el marxismo, la religión o el europeísmo) ha dado paso al auge de otros más heterogéneos, entre los que destacan los de los partidos. En la pugna narrativa que hoy se vive, el descontento de las clases medias refuerza la polarización política. Los relatos clásicos de la izquierda (igualdad y justicia distributiva) y de la derecha (libertad e individualismo) son desplazados por relatos identitarios generando, como consecuencias, la subida electoral de partidos de extrema derecha o extrema izquierda y una creciente polarización parlamentaria.

Este concepto de storytelling, según el mundo anglosajón del que procede, nació en el mundo publicitario para narrar historias sobre productos en venta y marcas corporativas. Con el tiempo, la política ha sabido adueñarse de esta herramienta que contribuye a fomentar la unión entre los ciudadanos y los representantes políticos. Al igual que ocurre con productos y marcas, el storytelling aplicado a la política contribuye a sumergir al ciudadano en un universo narrativo que trata de ofrecerle mayor credibilidad y mayor sensación de fiabilidad. 
Los hechos demuestran que en la práctica no resulta sencillo lograr una narración que sea capaz de conectar realmente con las emociones del público a no ser que la historia sea real y que el material narrativo se corresponda a una realidad vital, la del propio candidato. Los aspirantes tienen que ganarse lo que el politólogo canadiense Michael Ignatieff denomina «el derecho a ser escuchado por los votantes» (Ignatieff, 2014). En la vida cotidiana, los expertos en cualquier materia científica poseen este derecho debido a sus conocimientos, pero en política es diferente. Un candidato se gana el privilegio a ser escuchado si el votante considera que es digno de confianza. Cuando no logra convencer a los electores de que está en política por ellos tampoco se puede hacer acreedor del derecho a ser escuchado.

\section{INTERNET GENERA UNA REVISIÓN GLOBAL DE LA COMUNICACIÓN POLÍTICA}

Vivimos un cambio estructural que es también un cambio cultural, ligado a lo que se ha llamado la "tercera revolución industrial": la primera fue impulsada por la máquina de vapor; la segunda llegó con la electricidad y el motor de combustión interna propulsado por combustibles fósiles; y la tercera es la de internet (Ferguson, 2018). El hecho es que los ciudadanos acceden a la información con otras herramientas más allá de las clásicas: prensa escrita, radio y televisión. Internet y las redes sociales dan lugar al paso de la "información" a la "comunicación política": la información, de carácter impositivo, se da en un contexto en el que el emisor ofrece los datos al receptor sin esperar respuesta. En cambio, la comunicación tiene un carácter más democrático porque establece un flujo de contacto bidireccional, un proceso del que se espera respuesta y en el que todos los participantes tienen voz. Esta democratización de la comunicación política es posible gracias a una sucesión de desarrollos tecnológicos que permiten mayor participación de diferentes sectores de la población en el ámbito político.

Internet, un sistema relativamente económico, ha permitido la entrada de nuevos actores al proceso electoral, ha posibilitado flujos constantes de contacto con la población, ha creado una ciudadanía permanente informada y más preocupada por participar en los procesos de toma de decisiones. La pasividad ha dado paso a la actividad. Desde la campaña de Barak Obama en 
2008 los partidos políticos ya no son los únicos productores de información y contenidos para las campañas, también lo son los propios ciudadanos. En España son ejemplos claros de esta tendencia las campañas de Podemos desde 2014 y el llamado "efecto Carmena" en las elecciones municipales madrileñas de 2015. Las empresas y los ciudadanos fueron los primeros en entender el cambio de paradigma tecnológico que representa internet. Las instituciones políticas y los partidos han ido a remolque, pero a unos y a otros les queda aún mucho por avanzar.

\section{GANA PROTAGONISMO EL ACTIVISMO CIUDADANO}

Internet potencia el papel del ciudadano como agente de comunicación política. Tradicionalmente, una campaña electoral dependía del candidato y del dinero que invertía él o su partido o ambos. Sin embargo, en 2014, una encuesta del CIS sorprendió con el dato de que la opinión pública valoraba mucho mejor la campaña de Podemos que la de cualquier otra formación política, a pesar de que ni siquiera existía cuatro meses antes y que apenas tenía fondos. Pablo Iglesias y sus compañeros de la Facultad de Ciencias Políticas de la Universidad Complutense de Madrid habían entendido que estaba cambiando la lógica tradicional de canalización política. Podemos se lanzó sin remilgos a la "nueva política", mucho más abierta, asamblearia, ligada a internet, dirigida a gente que está más preparada y con conocimiento accesible y compartido. Fueron los primeros en asumir que cuando se trata de la Red conviene "no confundir un martillo con Alemania", por utilizar la metáfora del catedrático Joan Subirats: algunos partidos ( $y$ otras instituciones) creen que internet es semejante a un martillo, una herramienta y, por tanto, pretenden utilizarla con los mismos esquemas mentales para seguir haciendo las mismas cosas por otros medios. Pero internet es Alemania, es otro país, otro idioma, otra cultura, otra manera de comportarse, que obliga a preguntarnos no solo cómo hacemos las cosas, sino las propias cosas que hacemos (Subirats, J. y Vallespín, F., 2015).

Dejando al margen la cuestión de la evolución ideológica de Podemos y la "nueva política", lo evidente por ahora es que los grandes partidos han perdido funcionalidad y capacidad representativa. Hay un debilitamiento del establishment político. En Alemania, Francia, el Reino Unido o Estados Unidos 
había en los años sesenta un establishment muy sólido: dos grandes partidos que controlaban las candidaturas, unos pocos canales de televisión que todo el mundo veía, unas limitadas fuentes de financiación... Eso ha cambiado. Hoy, un candidato puede darse a conocer y ganar adeptos y financiación a través de las redes sociales. Hay una democratización de las democracias que genera, en algunos casos, incertidumbre y populismo. En la actualidad, se puede rechazar al establishment y ganar votos. Es el caso de Donald Trump, el Movimiento Cinco Estrellas o Vox, pero también de Pedro Sánchez, que después de perder la secretaría general del PSOE desafió a la élite del partido para volver a recuperarla con la fuerza de las bases.

El hecho es que, desde la campaña de 2008, los partidos políticos ya no son los únicos y principales productores de información y contenidos para las campañas, sino los propios ciudadanos. Con el salto tecnológico representado por las redes sociales y los instrumentos de comunicación transversal, el debate ya no gira en torno a quién tiene derecho a votar, como ocurrió en los orígenes de la democracia representativa, sino quién tiene derecho a hablar y a dirigirse a una audiencia potencialmente masiva. Ese derecho correspondía hasta hace poco casi en exclusiva a las élites, las que controlaban la radio, la televisión y, en menor medida, la prensa escrita. Hoy es casi un derecho global gracias a internet. Lo cierto es que la democracia se basa en la participación, aunque los mecanismos de representación sean cada día más complejos.

En España se han difundido tímidamente, sobre todo en torno a Podemos, una técnica habitual en Estados Unidos: el grassroots organizing. Estas "organizaciones populares" consisten en la movilización de votantes a través de redes de ciudadanos activistas.

\section{INTERNET HA CAMBIADO TAMBIÉN EL NEGOCIO DE LA INFORMACIÓN}

Internet cambia el alcance del negocio de la información, tanto escrita como audiovisual. El paradigma profesional sigue siendo el mismo: contar y explicar la actualidad, respetando la verdad, mediante relatos interesantes, proporcionando oportunidades a voces que merecen ser tenidas en cuenta y con rigurosa distancia al morbo y a la extravagancia. Ben Bradlee, el célebre 
director de The Washington Post lo decía de forma tan sintética como acertada: "El fundamento del periodismo es buscar la verdad y contarla". (Bradlee, 1995, p. 577). Pero el hecho cierto es que tanto la prensa de papel, tradicional prescriptora del criterio editorial, como la televisión -gratuita, masiva, ligera pero poderosa- viven un proceso acelerado de cambio por el efecto de internet y eso ha descalabrado sus cuentas de resultados económicos. Según la Federación de Asociaciones de Periodistas de España, la crisis financiera que comenzó en 2008 generó la pérdida de 13.000 empleos y decenas de empresas cerradas.

Resulta paradójico que en la era de la globalización, que es también la de la información, el negocio periodístico esté atravesando por su peor crisis de modelo. No obstante, los mejores diarios del mundo y de España están activando el modelo de suscripción digital, al rebufo del buen funcionamiento de plataformas de entreteniendo como Spotify o Netflix, como medio para poder salvar sus cuentas de resultados.

Sea como fuere, la apuesta por el periodismo de calidad es importante para la sociedad en cuanto que se trata de uno los pilares de la democracia, según recoge la Constitución de 1978 es su artículo 20.1.: se reconoce y protege el derecho a comunicar o recibir libremente información veraz por cualquier medio de difusión. A este respecto, los profesores Steven Levitsky y Daniel Ziblatt demuestran en su ensayo Cómo mueren las democracias (2018) que las democracias ya no terminan con un bang (un golpe militar o una revolución) sino con un leve quejido: el lento y progresivo debilitamiento de las instituciones esenciales (la justicia, el parlamento o los medios de comunicación) y la erosión de las normas políticas tradicionales.

\section{MULTIPLICACIÓN DE BULOS Y NOTICIAS FALSAS}

Los bulos que se lanzan con el propósito de engañar, de modificar un estado de la opinión pública, son viejos como la humanidad (Pizarroso, 2005). Es un fenómeno muy antiguo, pero la capacidad de proyección y propagación de las modernas tecnologías de la comunicación favorece como nunca la circulación de noticias falsas, de historias fabricadas o de propaganda disfrazada de información. Se difunden rápidamente sobre todo porque los usuarios no verifican la fuente y comparten la noticia por su atractivo o su impacto. Vídeos y 
memes circulan incesantemente por las redes sociales, que los propios receptores contribuyen a viralizar. Los bulos viven en la actualidad una época de apogeo, bajo el término inglés fake news, del brazo de la posverdad y los "hechos alternativos", sobre todo desde la campaña que llevó a Donald Trump a la presidencia de Estados Unidos en 2016.

En democracias muy polarizadas por el auge del populismo, las noticias falsas sobre política pretenden influir en la opinión pública, como se observó en las elecciones presidenciales estadounidenses de 2016 o en el referéndum del Brexit. Las fake news tienen un fin propagandístico y también económico, puesto que permiten llegar a un gran número de personas en un tiempo mínimo y generan unos relevantes ingresos, dado que los clics en las noticias se traducen directamente en dinero gracias a los anunciantes y la compraventa de los datos de los usuarios.

Las redes han multiplicado hasta el infinito el tráfico de información falsa utilizando campañas de bots (cuentas automatizadas en Twitter, falsas o no, que amplifican mensajes realizando miles de retuits o likes o engrosando cuentas de seguidores) y trols (usuarios que malmeten, insultan, jalean, generan ruido, desinforman y difunden bulos) con extraordinaria eficiencia.

Las fake news se han consolidado porque muchos ciudadanos creen que mirando en la pequeña pantalla de su teléfono móvil una sensacional cascada de titulares impactantes, imágenes fuertes, violentas y espectaculares, pueden estar informados de la actualidad. En realidad, ni las redes sociales ni siquiera la televisión están estructuradas tanto para informar como para distraer. Además, la sucesión rápida de noticias breves y fragmentadas produce un doble efecto negativo de sobreinformación y desinformación.

Lo que están haciendo las nuevas tecnologías es hacer más sofisticados los engaños. Donde antes se lanzaba un rumor ahora lo hacen unas imágenes que parecen ciertas y que logran mucho más eco a través de su expansión por las redes sociales. Ni siquiera la herramienta de verificación más potente es capaz de desmontar una mentira tan bien elaborada. Al menos no antes de que haya hecho demasiado daño. En consecuencia, los bulos están consiguiendo, a través de las redes sociales, romper el espacio de debate público y promocionar ideologías basadas en el odio y el miedo. De paso, logran que el público recele de los mensajes de los medios. 


\section{LA COMUNICACIÓN BIDIRECCIONAL INCREMENTA LA VOLATILIDAD}

Internet, las redes sociales y las nuevas herramientas tecnológicas han revertido las lógicas comunicativas. Ya no estamos ante una comunicación unidireccional, sino ante otra en la que los ciudadanos pasan de ser meros receptores a generadores de comunicación. Favorecen así la transición de una "campaña permanente" a una "ciudadanía permanente". Del mismo modo que la prensa está informando de forma permanente sobre lo que sucede en el escenario político, y de la misma forma que los partidos viven en una campaña permanente, también se ha establecido un tipo de ciudadano que continuamente está evaluando su posición política. Esta transformación ha favorecido lo que se denomina "protocolos de escucha activa" (Sánchez Medero, 2016, p. 39). En otras palabras, la inclusión de las demandas colectivas en las agendas políticas de manera más inmediata. Además, las nuevas formas de comunicación de "relatos" favorecen la implicación y participación de los ciudadanos en estos procesos comunicativos.

Una consecuencia de este cambio de paradigma es que los procesos electorales resultan mucho más volátiles. Los partidos pierden el papel de intermediario entre el poder y los ciudadanos, como le pasó al Parlamento, en beneficio de asociaciones de vecinos o plataformas cívicas (Teruel Existe), ligas de marginados sociales (Stop desahucios), movimientos feministas, organizaciones ecologistas (Equo), sindicatos...

La política española, cada vez más, se vive y se registra en los medios de comunicación y las redes sociales sobre la idea de la "campaña permanente". En parte porque las nuevas formas de participación política permiten un "empoderamiento" de los ciudadanos. Claro que no todas las personas participan con la misma intensidad. Sánchez Medero plantea que existe una brecha social entre aquellos ciudadanos que han tenido acceso a un nivel mayor de formación y aquellos que no lo han tenido. Son los primeros los únicos que pueden entender y procesar la ingente cantidad de información que la red ofrece. Este factor compromete la tendencia hacia la democratización de la comunicación política. 


\section{LA GRAN MANIPULACIÓN COMUNICATIVA: DEL CONFLICTO SOCIAL AL IDENTITARIO}

A finales del siglo pasado, los más influyentes ensayistas de la época, desde el británico Anthony Giddens y su "tercera vía" al estadounidense Richard Rorty y su pragmatismo, interpretaron que el espíritu de los tiempos, el zeitgeist, era que había que asumir la inevitabilidad del capitalismo global como el menos malo de los modelos. Tras la caída del Muro de Berlín, lo proclama Francis Fukuyama en su "Fin de la Historia". La crisis financiera que comenzó en 2008 dinamitó ese paradigma. Desde entonces, la desigualdad recupera la primacía como el principal problema económico, social y político de Occidente. Lo denuncian múltiples voces: Thomas Piketty, Tony Judt o Antón Costas. Lo llamativo es que el debate público no gira hoy en torno al reparto de la riqueza producida. El éxito del nuevo populismo conservador es que ha conseguido situar en el epicentro los conflictos de identidad. Donald Trump, Boris Johnson, Marie Le Pen, Steve Bannon, Carles Puigdemont, Santiago Abascal... han logrado convertir la fractura económica en una cultural. Desprecian la clásica moderación conservadora y practican una agresiva política de miedos (al crimen, al terrorismo, al paro, al declive económico, a la pérdida de los valores nacionales) rompiendo así los consensos morales y lanzando nuevas guerras culturales (Fukuyama, 2019).

Esta tendencia está detrás del gran auge en la actualidad de la polarización política y los populismos (Vallespín F. y Martínez-Bascuñán, M. 2017). Sin duda se trata de un gran éxito comunicativo que demuestra que el resultado del juego de la política depende de cuál, de la multitud de posibles conflictos, gana la posición dominante. Esta es la tesis que defendió, ya en los años sesenta, Elmer Eric Schattschneider. En lugar de un sistema esencialmente democrático en el que los muchos intereses en competencia de los ciudadanos están ampliamente representados, el politólogo estadounidense argumentó que el sistema de presión está sesgado a favor de los miembros mejor educados y de mayores ingresos de la sociedad (Schattschneider, 1960). 


\section{PROFESIONALIZACIÓN DE LA ASESORÍA Y LA COMUNICACIÓN POLÍTICAS EN TORNO A LOS HIPERLIDERAZGOS}

La democratización de la comunicación política y las nuevas dinámicas comunicativas ligadas a internet no han frenado la continua implantación del márquetin político de influencia anglosajona. Conseguir un encuentro óptimo entre la oferta y la demanda continúa siendo el objetivo principal. Sin embargo, sí han modificado su enfoque. Las estrategias inclusivas y el empleo de nuevos canales de comunicación ofrecen a los partidos y candidatos elaborar propuestas más personalizadas y atender mejor a las demandas de la ciudadanía. A cambio, se siguen construyendo mensajes que, para muchos, siguen vacíos de contenidos.

El marketing político, que es aún más sofisticado que la publicidad o la propaganda, integra todas las herramientas que van surgiendo con tal de aumentar el mercado electoral: redes sociales, recogida de datos de una manera estructurada, neuromarketing y, sobre todo, el papel de los asesores. Los partidos contratan los servicios de los profesionales de la comunicación política y la publicidad, el marketing, las relaciones públicas... a los que encargan las campañas y las estrategias de comunicación. De hecho, en los mandatos gubernamentales de Pedro Sánchez, en España se ha dado un paso más en esta tendencia: la gran novedad en la "fontanería monclovita" ha llegado con Iván Redondo. Se trata de un profesional de la asesoría política que, por primera vez, no es solo un consejero, como Pedro Arriola con Rajoy y Aznar, sino que es el jefe de gabinete del presidente del Ejecutivo. Su modelo de asesoramiento, al estilo americano, es de adhesión absoluta al líder y no a su formación política. Se mueve organizando golpes de efecto, como cambiar el día del Consejo de Ministros del viernes al martes para dominar la agenda informativa de la semana. Está al mando de la acción política del Presidente, maneja su agenda, toma decisiones de gestión cada día. En el PSOE, ese puesto siempre fue para un hombre del partido, como José Enrique Serrano, que lo fue con González y con Zapatero. Sin embargo, Redondo, aunque fue jefe de gabinete de un presidente autonómico del PP (José Antonio Monago), hoy tiene la confianza absoluta de Sánchez. Este "mercenario" de la política es un buen paradigma de la actual profesionalización de la comunicación.

En el nuevo marketing político, el de las tres "t" (tecnología, tecnócratas y técnicas), los asesores del candidato son más importantes incluso que su 
propio partido. Con frecuencia, los bandazos ideológicos y estratégicos de unos y de otros son la consecuencia de esta pasión por las encuestas y los cálculos electoralistas. Ahí está el caso de Albert Rivera (Ciudadanos), que en 2019 no quiso pactar con el PSOE cuando sumaban mayoría absoluta. O el de Isabel Díaz Ayuso, Presidenta de la Comunidad de Madrid y "verso libre" dentro del PP con el asesoramiento de Miguel Ángel Rodríguez, que ya fue portavoz y Secretario de Estado de Comunicación del Gobierno de José María Aznar.

Es evidente la profesionalización de los partidos y de la política. El líder se independiza respecto a la organización y se transforma en el epicentro de la campaña. La ideología se difumina en beneficio del infoentretenimiento y la mediatización para convertir al líder en líder de visibilidad. Los hiperliderazgos están reemplazado así a los viejos partidos, aquellos de los frenos y contrafuertes, por un nuevo tipo de organización posmoderna, con estructuras virtuales y todo el poder concentrado en el hiperlíder y en sus consejeros áulicos. Se ha acabado con la costumbre de prestar atención a los barones y otras figuras relevantes del partido pues lo que importan son los sondeos y los impactos en las redes sociales. La dilatada experiencia en política ya no es un grado, sino que es visto como un lastre porque el veterano, curtido en mil batallas, suele tener la vista puesta en el largo plazo.

\section{UNA COMUNICACIÓN POLÍTICA VOLCADA EN EL MANEJO DE DATOS}

La mayor fluidez informativa y comunicativa que proporciona internet genera cantidades ingentes de datos personales de los ciudadanos. $\mathrm{Y}$ el tratamiento de estos datos ofrece la posibilidad de un control social de dimensiones inimaginables. Las elecciones cotidianas de las personas se pueden automatizar a través de algoritmos más o menos opacos que ya controlan sus gustos, deseos y conocimientos. Una consecuencia comunicativa de esta nueva dinámica es que instituciones y partidos políticos quieren utilizar estos datos con fines electorales. En la era del big data, el detalle que pueden obtener de sus potenciales votantes no tiene precedentes. Todas las capacidades de segmentación pueden ser y son empleadas también en el ámbito político. Gracias a una adecuada segmentación que se consigue 
mediante la gestión del big data pueden elaborar contenidos muy personalizados. De este modo, pueden convencerlos mejor de que les voten.

En España, desde el 5 de diciembre de 2018, la Ley Orgánica de Régimen Electoral General permite a los partidos recopilar, en internet y en otras fuentes públicas, datos personales sobre las opiniones políticas de los ciudadanos para realizar perfiles ideológicos. La legislación básica que regula los comicios considera que esta capacidad de los partidos para recabar los datos para las campañas electorales está amparada en el interés público, y el único límite que fija para esta actividad es ofrecer las "garantías adecuadas" para que los datos tratados no permitan identificar a las personas que los depositaron.

Algunos juristas consideran que esta posibilidad, regulada en el artículo 58 bis. 1 de la ley electoral, atenta contra derechos fundamentales de la Constitución. Diego López Garrido, por ejemplo, cree que permitir a los partidos la recolección de datos sobre opiniones políticas es contrario a los artículos 18.4 y 16 de la Constitución Española (Pérez, F. 2019). El primero recoge el derecho fundamental a la protección de los datos personales y el segundo garantiza la libertad ideológica de las personas. López Garrido considera que este artículo vulnera también el artículo 8 de la Carta de Derechos Fundamentales de la UE, sobre la protección de datos de carácter personal.

Más allá de este debate jurídico de ámbito español, es evidente que la opinión pública mundial ha entrado es una nueva dimensión de la propaganda ideológica (Lasalle, 2019). Los centros de poder, sean viejos (los gobiernos) o nuevos (los gigantes tecnológicos como Google, Facebook, Amazon y Apple) van a explotar esta ventaja propagandística porque necesitan ganar la batalla de la persuasión imponiendo su relato.

\section{BIBLIOGRAFÍA}

- BADLEE, B. (1995). La vida de un periodista. Madrid: El País Aguilar.

- CASTELLS, M. (2009). Comunicación y poder. Madrid: Alianza Editorial.

- ChARAUDEAU, P. (2003). El discurso de la información: La construcción del espejo social. Barcelona: Gedisa. 
- CHOMSKY, N. y HERMAN, E. (1990), Los guardianes de la libertad. Propaganda, desinformación y consenso en los medios de comunicación de masas, Barcelona: Crítica.

- EIXARCH J. F. (2019). "La cultura del entretenimiento amenaza la supervivencia de la democracia”. Heraldo de Aragón, 21/11/2019.

- FERGUSON, N. (2018). La plaza y la torre. Barcelona: Debate.

- FUKUYAMA, F. (1992). El fin de la historia y el último hombre. Barcelona: Planeta.

- (2019). Identidad. Barcelona: Deusto.

- GRABER, D. (1997), Mass Media and American Politics, Congressional Quarterly Press, Washington.

- HALLIN, D. citado por Marín, J., Luengo, O., Ergül, H. y Gökalp, E. (2009). El conflicto en Gaza: el papel de la prensa en España y Turquía. Disponible en: http://www.aecpa.es/uploads/files/congresos/congreso_09/grupostrabajo/area07/GT02/07.pdf (Consultado el 12-08-2015).

- IGNATIEFF, M. (2014). Fuego y cenizas. Éxito y fracaso en la política, Madrid: Taurus.

- LASALLE, J. M. (2019). Ciberleviatán: El colapso de la democracia liberal frente a la revolución digital. Barcelona: Arpa Editores.

- LEVITSKY, S. y ZIBLATT, D. (2018), Cómo mueren las democracias, Barcelona: Ariel.

- LIPPMANN, W. (2003). La opinión pública, Madrid: Langre.

- LUHMANN, N. (2000). La realidad de los medios de masas. Barcelona: Anthropos.

- MILLER, D. (Ed.) (2004). Propaganda and Media Distortion in the Attack on Irak, Londres: Pluto Press.

- O'HEFfERNAN, P. (1991). Mass Media and American Foreign Policy: Insider Perspectives on Global Journalism and the Foreign Policy Process. Norwood: Ablex Publishing. Citados ambos en Marín, J., Luengo, O., Ergül, H. y Gökalp, E. (2009). op. cit., p. 5. 
- ORREN, G. (1986) "Thinking about the Press and Government", en Linsky, M. (ed.) In How the Press Affects Federal Policymaking. Nueva York: Norton, Nueva York.

- PÉREZ, F. (2019). "Juristas rechazan que los partidos puedan recopilar datos sobre opiniones políticas de los ciudadanos". El País. 4 de marzo. Disponible en:

http://www.elpais.com/politica/2019/03/03/actualidad/1551635207_608335. html [Consultado 11-10-2019].

- PIZARROSO, A. (2005). Nuevas guerras, vieja propaganda. De Vietnam a Irak. Madrid: Cátedra.

- RAWLS, J. (2009). Lecciones sobre la historia de la filosofía política. Barcelona: Paidós.

- RUEDA, J. J. (2015), "Periodismo en un nuevo escenario global", en Innerarity, D. y otros, Impacto de la crisis en el proyecto europeo, Seminario de Investigación para la Paz-Cortes de Aragón, Zaragoza, 2015, pp. 335-350.

- SÁNCHEZ MEDERO, R. (Coordinador) (2016). Comunicación Política. Nuevas dinámicas y ciudadanía permanente, Madrid: Tecnos.

- SARTORI, G. (1998), Homo videns. La sociedad teledirigida, Madrid: Taurus.

- SCHATTSCHNEIDER, E. (1960). El pueblo semisoberano: una visión realista de la democracia en Estados Unidos. México: Manuales Uteha.

- SUBIRATS, J. y VALLESPÍN, F. (2015). España/Reset: Herramientas para un cambio de sistema, Barcelona: Ariel.

- VALLESPÍN F. y MARTíNEZ-BASCUÑÁN, M. (2017). Populismos. Madrid: Alianza Editorial.

- YANES, R. (2009). Comunicación política y periodismo. Madrid: Fragua. 